\title{
Depression following Acute Spinal Cord Injury
}

Fiona K. Judd, M.B., B.S., D.P.M., M.R.A.N.Z.C.P., ${ }^{1}$ G. D. Burrows, M.D., Ch.B., B.Sc., D.P.M., F.R.A.N.Z.C.P., F.R.C.Psych., ${ }^{1}$ D. J. Brown, M.B., B.S., F.R.A.C.P. ${ }^{2}$

${ }^{1}$ University of Melbourne, Department of Psychiatry, ${ }^{2}$ Spinal Injuries Unit, Austin Hospital, Heidelberg, 3084, Australia

\begin{abstract}
Summary
Nine patients meeting the DSM-111 criteria for major depressive episode were identified among 84 consecutive admissions to the Spinal Injuries Unit of the Austin Hospital. All were successfully treated with antidepressants. The means of recognition of depression, the differentiation of a depressive illness from grief and the implications for rehabilitation are discussed.
\end{abstract}

Key words: Spinal injury; Depressive illness; Antidepressants.

\section{Introduction}

The literature contains much theoretical discussion about depression in patients with spinal cord injury, but provides little evidence to support claims made. Some writers have stated depression should be considered normal for all patients (Witthower, et al. 1954, Stewart, 1977a, Bracken and Shepherd, 1980), that depression is an inevitable consequence of spinal cord injury (Hohman, 1975; Stewart, 1977b) and that spinal patients who are not depressed are cause for concern (Tiller, 1969).

Few studies exist which systematically assess the incidence of depressive illness. Lawson (1978) studied ten male quadriplegic patients for the entire duration of their stay in a rehabilitation hospital (mean 109 days). All had been injured 70 days or less prior to admission to the hospital. Therapists working with the patients and the patient himself completed daily emotion report forms from which daily depression scores were obtained. No clear periods of depressive affect were found. Fullerton, et al. (1981) studied 15 quadriplegic and 15 paraplegic patients admitted to a rehabilitation unit. All patients had sustained spinal cord injury in the previous six months. All were interviewed within one week of arrival in the rehabilitation ward, using the schedule for Affective Disorders and Schizophrenia (Lifetime version) (SADS-L) and retrospective diagnoses made according to the Research Diagnostic Criteria (RDC). Fifteen patients had no RDC diagnosis prior to or following the injury. One patient 
had a past history of depressive illness. Nine patients were depressed after injury. Depression was not an extension of pre-injury problems, but developed after injury. Eight depressive disorders developed within one month of injury. One did not become depressed until three months after injury. All depressive disorders had resolved at the time of discharge (mean follow-up 12 weeks).

Trieschmann (1980) in her in-depth review of these many theoretical and few available clinical studies, has concluded that spinal injury does not lead to severe depressive reactions in all patients and the absence of depression does not seem to imply denial of illness or poor adjustment to disability.

Depressive illness must be differentiated from other mood disorders including despondency and grief, from conservation-withdrawal and from regression. Despondency is a common reaction to serious illness, but is generally brief, non-pervasive, fluctuating and not accompanied by the vegetative, cognitive and behavioural symptoms of depression.

Grief is the complex emotional response to loss which may be manifested as a wide variety of affects including sadness, anger, guilt, anxiety, hopelessness and despair. Most people who experience a loss, describe themselves as feeling 'depressed'. Generally they are describing feelings of sadness. The typical grief reaction includes a number of phasic responses-stunned disbelief, yearning and pining for return of the lost object and angry protest at its withdrawal, and finally despair and gradual relinquishment of what is lost. Behaviour during these phases may include denial, anger, guilt, bargaining, acting out, somatisation and depressed mood (Raphael, 1977; Parkes 1972). Grief in the disabled individual has been attributed to a loss of self (Adams \& Lindeman, 1974; Sakinofsky, 1980; Viney \& Westbrook, 1982). Raphael (1977) has suggested the following points as clinically useful in differentiating grief and depressive phenomenology-sleep disturbance, appetite disturbance, general somatic symptomatology, despair, hopelessness, anger, guilt (Table I). The nature of spinal injury itself and the effects of treatment may make interpretation of some of these signs difficult.

Conservation-withdrawal has been described as the ordinary self-limited biologic reaction pattern of withdrawal and inactivity that protects the organism against overstimulation or excessive deprivation (Engel, 1979). Physical and psychological concomitants of conservation-withdrawal such as weakness, fatigue, diminished energy, diminished muscle tone, and loss of interest in the environment may readily be confused with symptoms of depression. Unlike depressive illness, a pure conservation-withdrawal response is affectively neutral. (Weiner and Lovitt, 1979).

A depressive illness is characterised by a pervasive lowering of mood, with loss of interest or pleasure in all or almost all activities and pastimes. Accompanying symptoms include sleep and appetite disturbance, psychomotor retardation or agitation, loss of energy or fatigue, feelings of worthlessness, self-reproach or excessive or inappropriate guilt, poor concentration and slowed thinking or indecisiveness and recurrent thoughts of death, suicidal ideation or suicide attempt. The DSM-111 diagnostic criteria (American Psychiatric Association 1980) for major affective disorder are shown in Table II.

Failure to recognise a depressive illness, to differentiate grief from depression, or the incorrect assumption that depression is a 'normal response' or part of a 
Table I

\begin{tabular}{|c|c|c|}
\hline & Grief & Depressive illness \\
\hline Sleep disturbance & $\begin{array}{l}\text { Most marked in early period } \\
\text { following loss, no fixed } \\
\text { pattern }\end{array}$ & $\begin{array}{l}\text { Distinct pattern } \\
\text { Long lasting } \\
\text { Worsens with time }\end{array}$ \\
\hline Appetite disturbance & $\begin{array}{l}\text { Waves of growing discomfort } \\
\text { Appetite gradually improves } \\
\text { Lose weight }\end{array}$ & $\begin{array}{l}\text { Total disinterest in food- } \\
\text { Gradually worsens } \\
\text { Lose weight }\end{array}$ \\
\hline $\begin{array}{l}\text { General somatic } \\
\text { symptomotology }\end{array}$ & $\begin{array}{l}\text { Transitory } \\
\text { Shortness of breath, tiredness } \\
\text { Tension, anxiety symptoms }\end{array}$ & $\begin{array}{l}\text { Constipation, dry mouth } \\
\text { General anergia } \\
\text { Pain }\end{array}$ \\
\hline $\begin{array}{l}\text { Despair and } \\
\text { hopelessness }\end{array}$ & $\begin{array}{l}\text { Lessens as mourning progresses } \\
\text { little self-preoccupation }\end{array}$ & $\begin{array}{l}\text { Preoccupied with sense of } \\
\text { worthlessness }\end{array}$ \\
\hline Anger & $\begin{array}{l}\text { Expressed } \\
\text { Directed towards others }\end{array}$ & $\begin{array}{l}\text { Often not expressed/seen } \\
\text { as hostile demanding behaviour }\end{array}$ \\
\hline Guilt & Minimal in uncomplicated grief & Guilty preoccupations \\
\hline
\end{tabular}

Table II Major affective disorder (DSM-III)

A. Dysphoric mood or loss of interest or pleasure in all or almost all usual activities and pastimes. The dysphoric mood is characterised by symptoms such as the following: depressed, sad, blue, hopeless, low, down in the dumps, irritable. The mood disturbance must be prominent and relatively persistent, but not necessarily the most dominant symptom, and does not include momentary shifts from one dysphoric mood to another dysphoric mood, e.g. anxiety to depression to anger, such as are seen in states of acute psychotic turmoil.

B. At least four of the following symptoms have each been present nearly every day for a period of at least 2 weeks (in children under six, at least three of the first four):

(1) poor appetite or significant weight loss (when not dieting) or increased appetite or significant weight gain.

(2) Insomnia or hypersomnia.

(3) Psychomotor agitation or retardation (but not merely subjective feelings of restlessness or being slowed down).

(4) Loss of interest or pleasure in usual activities, or in sexual drive not limited to a period when delusional or hallucinating.

(5) Loss of energy; fatigue.

(6) Feelings of worthlessness, self-reproach, or excessive or inappropriate guilt (either may be delusional).

(7) Complaints or evidence of diminished ability to think or concentrate, such as slowed thinking or indecisiveness not associated with marked loosening of associations or incoherence.

(8) Recurrent thoughts of death, suicidal ideation, wishes to be dead, or suicide attempt.

'phase of adjustment' to spinal cord injury may adversely influence both the short and long term rehabilitation of the spinal cord injured patient. In an attempt to clarify some of these questions, a pilot study was conducted to assess the incidence and treatment response of patients with depression following spinal cord injury. 


\section{Patients and methods}

All patients consecutively admitted to the Spinal Injuries Unit of the Austin Hospital between $1 / 10 / 84-30 / 11 / 85$ who did not have a significant head injury were included in the study. The Austin Hospital Spinal Injuries Unit admits patients who have sustained acute spinal cord damage as a result of an accident. Almost all patients were admitted within 6 hours of injury. Patients are referred from Victoria, Tasmania and the southern Riverina area of New South Wales. Patients with spina bifida or progressive disease, e.g. cancer or multiple sclerosis, which has caused damage to the spinal cord, are not admitted to this unit.

Each of 84 patients meeting the study criteria were interviewed by the Spinal Injuries Unit liaison psychiatrist within 2 weeks of admission. A current diagnosis of depression or other psychiatric illness was made following detailed clinical interview, mental status examination and completion of the 17-item Hamilton Depression Rating Scale (HDRS) (Hamilton, 1960). Patients were then observed for the duration of their hospital admission by members of the multi-disciplinary treatment team, and were re-assessed by the psychiatrist if they showed any signs of depression. All psychiatric diagnoses were made according to DSM-111 criteria (American Psychiatric Association 1980). Severity of depressive illness was quantified using the HDRS. Diagnoses were sub-divided to those predating or occurring for the first time after injury. For those beginning after injury, date of onset was determined. The occurrence of transient acute organic brain syndrome (delirium) is not reported here.

\section{Results}

The eighty-four patients included in the study ranged in age from 18 to 84 years (mean 35.5 years). Seventy-one were male and 13 were female. Fifty-two were paraplegic, and 32 quadriplegic. Of the total 84 patients, 65 did not qualify for any DSM-111 axis 1 diagnosis before or after spinal cord injury. Three patients admitted to the unit were subsequently found to have conversion symptoms and discharged shortly after assessment. Three patients met the DSM-111 criteria for alcohol dependence, one for substance (opiate) dependence, one for mild mental retardation, one for panic disorder and one for schizophrenia. All diagnoses except panic disorder pre-dated the spinal cord injury.

Nine patients met the DSM-111 diagnostic criteria for major affective disorder (Table III). These patients were predominantly male $(\mathrm{N}=8)$ and ranged in age

Table III Patients with DSM-111 major affective disorder

\begin{tabular}{cccccc}
\hline Age & Sex & Level & Time after injury & Treatment & Maximum dose \\
\hline 64 & M & T11 & 4 months & Mianserin & $100 \mathrm{mg} /$ day \\
27 & M & C4 & 3 months & Mianserin & $140 \mathrm{mg} /$ day \\
65 & M & C5 & 5 months & Nomifensine & $450 \mathrm{mg} /$ day \\
70 & M & C6 & 2 weeks & Mianserin & $80 \mathrm{mg} /$ day \\
66 & M & C5 & 2 months & Mianserin & $80 \mathrm{mg} /$ day \\
40 & F & T2 & 4 weeks & Mianserin & $100 \mathrm{mg} /$ day \\
32 & M & L2 & pre-dated injury & Nomifensine & $400 \mathrm{mg} /$ day \\
28 & M & C6 & 2 months & Nomifensine & $200 \mathrm{mg} /$ day \\
19 & M & T11 & 6 weeks & Nomifensine & $200 \mathrm{mg} /$ day \\
\hline
\end{tabular}


from 19-70 years (mean 45.6). Five were quadriplegic and four paraplegic.

Time of onset of depression ranged from 2 weeks to 5 months after the spinal injury. One of the nine patients had a past history of bipolar affective disorder. This patient's spinal injury was the result of a failed suicide attempt, made at the time of a major depressive episode. Scores on the 17 item Hamilton Depression Rating Scale ranged from 26-44 (mean score 32.6). All patients described generalised somatic symptoms (item 13), some degree of hypochondriasis (item 15) and weight loss (item 16). These to some degree were attributed to the spinal injury itself and not necessarily assumed to be depressive symptoms.

All nine patients were treated with antidepressant medication and supportive psychotherapy. Antidepressant drugs used were mianserin $(\mathrm{N}=5)$ and nomifensine $(N=4)$. All were significantly improved with medication with minimal side effects. The time course of improvement was consistent with that usually seen with antidepressant medication. Alleviation of anxiety was evident within the first week of treatment but significant improvement in depression (HDRS < 17) did not occur until 3-6 weeks after commencing treatment.

\section{Discussion}

A discrete and treatable depressive illness was identified in 9 of 84 consecutive admissions to the Spinal Injuries Unit. One patient was suffering from depression at the time of admission, eight developed a depressive illness after their injury. We were able to separate depressive illness from grief by history, mental status examination and interview with the patient's family. Unlike those patients experiencing 'normal grief', our depressed group described a qualitative and persistent change in mood, loss of interest in themselves, the environment and their families, insomnia not simply due to environmental disturbances, difficulty with concentration and memory, thinking and decision making. Anxiety and irritability was marked in the elderly depressed patients. Several described suicidal ideation, phenomenologically distinct from the ambivalent suicidal thoughts often described in the early stages following spinal cord injury. While many of the physical signs of depression may be lost in the spinal injured, the characteristic facial appearance of the depressed patient, with a furrowed brow, immobile face, downturned mouth and an expression of troubled perplexity is not influenced by spinal injury and was observed in the more severely depressed in our group.

The validity of the use of traditional interview schedules, depression rating scales and operational diagnostic criteria in spinal injured patients is not established. We used the DSM-111 diagnostic criteria for major affective disorder and the Hamilton Depression Rating Scale to quantify severity of illness. We believe this to be valid but it must be recognised that preoccupation with bodily function, weight loss, anergia, sleep disturbance may be the result of the injury, the treatment programme or part of a depressive illness, and the use of and interpretation of diagnostic criteria and rating scales must be appropriately modified. In particular somatic symptoms, bodily preoccupation and weight loss (items 13, 15, 16 HDRS) should be interpreted with caution.

All 9 of the depressed patients in the present study improved following prescription of antidepressant medication. As anticholinergic and autonomic 
side effects of tricyclic antidepressants and monoamine oxidase inhibitors may be troublesome in the spinal cord injured, our patients were treated with either mianserin or nomifensine, both 'second-generation' antidepressants with fewer anticholinergic or cardiotoxic effects. Both drugs were well tolerated in similar doses to those prescribed in the non-spinal injured population.

Unrecognised and untreated depressive illness may markedly impair both short and long term rehabilitation following spinal cord injury. Further research in this area is needed. In particular, efforts should be directed to early detection of depression, more reliable means of diagnosis, the use of biological markers of depression such as the dexamethasone suppression test (DST) and the evaluation of various treatment modalities.

\section{References}

Adams J, Lindeman E 1974 Coping with long term disability. In: Coelho G, Hamburg D, Adams J (Eds): Coping and Adaptation. New York: Basic Books, Inc., pp. 127-138.

American Psychiatric Association 1980 Diagnostic and Statistical Manual of Mental Disorders, 3rd edition, A.P.A. Washington D.C.

BRACKEN MG, SHEPARD MJ 1980 Coping and adaptation following acute spinal injury. A Theoretical analysis. Paraplegia 18:74-85.

ENGEL GL 1979 Conservation-withdrawal: Dysphoria and Depression. A biopsychosocial model. Presentation at University of Texas Health Science Center at Dallas.

Fullerton DT, Harvey RF, Klein MH, et al. 1981 Psychiatric disorders in patients with spinal cord injuries. Archives of General Psychiatry 38:1369-71.

Hamilton M 1960 A rating scale for depression. Journal of Neurology, Neurosurgery and Psychiatry 23:56-62.

HohmanN G 1975 Psychologic aspects of treatment and rehabilitation of the spinal injured person. Clinical Orthopaedics 112:81-88.

LAWSON N 1978 Significant events in the rehabilitation process. The spinal cord patient's point of view. Archives of Physical Medicine and Rehabilitation 59:573-579.

PARKes CM 1972 Bereavement: Studies of Grief in Adult Life. New York: International Universities Press, Inc.

RAPHAEL B 1977 The management of bereavement. In: BuRrows GD (Ed.) Handbook of Studies in Depression, Excepta Medica, pp. 367-378.

SAKINOFSKY I. Depression and suicide in disabled. In: BIsHOP DS (Ed.) Behavioural problems and disabled. Baltimore: Williams and Williams Company, 1980; pp. 17-51.

SILLER J 1969 Psychological situation of the disabled with spinal cord injuries. Rehabilitation literature 30:290-296.

STEwART TD 1977a Spinal Cord Injury: A role for the psychiatrist. American Journal of Psychiatry 134:538-541.

STEWART TD 1977b Coping behaviour and the moratorium following spinal cord injury. Paraplegia 15:338-342.

TrieschmanN RB 1980 Spinal Cord Injuries. Psychological Social and Vocational Adjustment. Pergamon Press, New York, pp. 35-85.

VINEY LL, WestBRoOK MT 1982 Coping with chronic illness; mediating role of biographical and illness-related factors. Journal of Psychosomatic Research 26:595-605.

Weiner MF, Lovitt R 1979 Conservation-withdrawal versus Depression. General Hospital Psychiatry 4:347-349.

Witthower E, Gingrao, Megier L, et al. 1954 A combined psychosocial study of spinal cord lesions. Journal of the Canadian Medical Association 71:109-115. 